\title{
WHO reports progress in malaria control
}

Published at www.cmaj.ca on Dec. 17, 2009

$\mathrm{W}$

hile international funding to fight malaria has more than doubled in the past three years, producing positive results, much more money is needed, according to a new report from the World Health Organization (WHO).

The World Malaria Report 2009, released Dec. 15, states that international funding commitments to combat the disease totalled US $\$ 1.7$ billion in 2009, up from US\$730 million in 2006. This is still far from the US\$5 billion needed every year to effectively treat and prevent malaria around the world, states the report (www.who.int /malaria/world_malaria_report_2009 /en/index.html).

"The funding for malaria is at an alltime high right now, which is good news, but it is far below what we need to seriously contemplate global control, much less elimination. And, my fear is that the key source of funds for malaria control, the Global Fund, is starting to lose its ability to attract the donor funding it needs to keep running," Matthew Lynch, director of the Global Program on Malaria at the Johns Hopkins Bloomberg School of Public Health in Baltimore, Maryland, wrote in an email.

Still, the increase in funding has allowed for a scale-up in malaria control interventions in some countries. In African countries, for example, $31 \%$ of households owned an insecticidetreated net in 2008 compared to $17 \%$ in 2006. In 13 African countries that have been hit particularly hard by the disease, net ownership now stands at greater than 50\%. The report also notes that more children under age five are sleeping under nets than in previous years.

"The good news in this report is that the problem improves with the integrated and widespread use of the interventions and treatments that expanded funding has enabled. All these efforts have led to real, measurable progress that translates into lower childhood

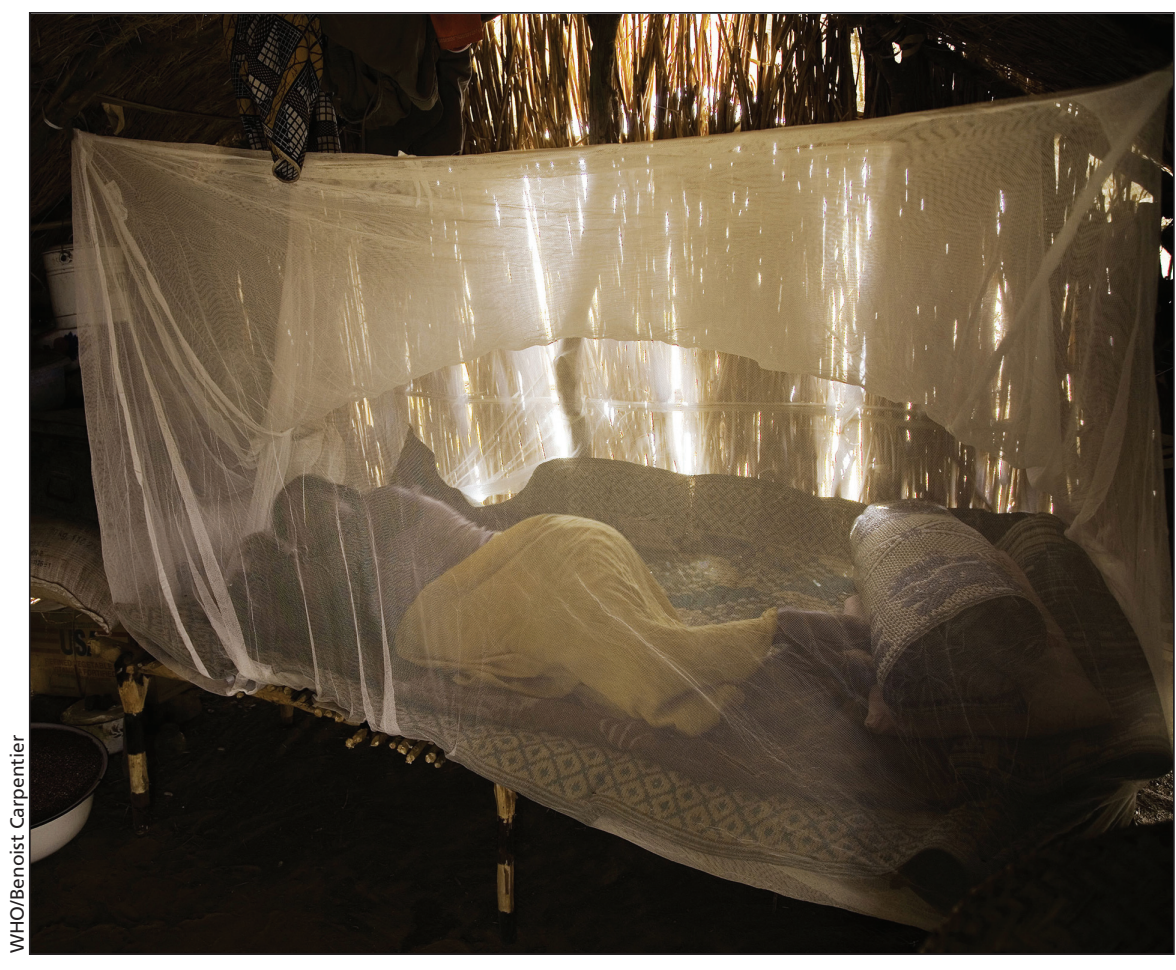

Insecticide-treated nets were found in $31 \%$ of African households in 2008 , as compared with $17 \%$ in 2006 .

mortality and fewer cases of this disease. However, it is equally clear that controlling malaria risk requires long term, intensive efforts on all fronts," Jeremy Kerr, a biology professor at the University of Ottawa in Ontario, who conducts research on how to identify regions at high risk of malaria, wrote in an email.

Approximately 240 million people were infected with malaria in 2008 , according to the WHO, and 863000 of them died. But of the 108 countries in which malaria is endemic, about a third had less than half of the number of cases of malaria in 2008 than in 2000. However, the countries with the highest rates of malaria, including Nigeria and the Democratic Republic of Congo, were the least successful in lowering their malaria burdens.

"While much remains to be done, the data presented here clearly suggest that the tremendous increase in funding for malaria control is resulting in the rapid scale-up of today's control tools," WHO Director-General Dr. Margaret Chan said in a press release. "This, in turn, is having a profound effect on health - especially the health of children in sub-Saharan Africa. In a nutshell, development aid for health is working."

The report demonstrates "that significant progress can be made in malaria control given sustained financing and improved distribution of control interventions such as ACTs [artemisinin-based combination therapies], bed nets and indoor residual spraying," Chris Hentschel, president and chief executive officer of Switzerland-based nonprofit Medicines for Malaria Venture, wrote in an email.

"It is heartening to see that use of ACTs in children with fever has increased somewhat to $15 \%$, but we need to radically improve these num- 
bers. There remains however a huge gap in financing and coverage if we are to move closer to malaria elimination in the main endemic areas of Sub Saharan Africa," Hentschel adds.

Others expressed concern that the report may leave an impression that malaria is under control. Richard Tren, director of Africa Fighting Malaria, a nonprofit health advocacy group, says that success in a few areas is not an accurate indicator of overall progress. Reached by email while traveling in the United Kingdom, Tren writes: "Overall the report does show an encouraging trend of declining malaria cases and deaths. This is good news and to be expected given the substantial increase in funding for malaria control. We do have a concern however that WHO and other stakeholders are playing up the successes when in reality the data are based on a few countries."

The report does, however, highlight ongoing areas of concern, including the lopsided distribution of funding. The vast majority of the money earmarked for malaria control is spent in smaller countries with lower disease burdens, it states. "More attention needs to be given to ensuring success in large countries that account for most malaria cases and deaths, and protecting the gains that have been made."

Another threat to controlling malaria, according to the report, is mosquito resistance to insecticides. Tren says the WHO offers no plan of action to address this problem and, in general, has a "blind spot" when it comes to insecticides. "This is a real problem to control insect borne diseases, we need insecticides," writes Tren. "The WHO has shown a remarkable lack of leadership on insecticides - routinely siding with environmental activists from the West against the interests of the poor and vulnerable living in poor countries."

While noting the major increase in donor funding for malaria control, Tren expresses concern that many countries struggling with malaria are not investing enough domestically to fight the disease and says that lasting success cannot be achieved with external dollars alone. Countries with rapidly growing economies, such as India and China, are receiving millions of dollars for malaria interventions that should go to countries that genuinely lack budgets for disease control, he says.

"This is a long tough road and we are by no means beating malaria progress is being made, but this disease can come back if success is claimed too soon," Tren writes. "There are an awful lot of policy problems that need to be dealt with - developing new insecticides one of the most important - and it seems like WHO and its partners are reluctant to do so." - Roger Collier, CMAJ

DOI: 10.1503/cmaj.109-3139 